\title{
Metastasis to Paranasal Sinuses as the First Presenting Sign of Renal Cell Carcinoma
}

\author{
Gustavo Ruschi Bechara, José Anacleto Dutra Resende Júnior, Hélio Assunção Gouveia, \\ Thomás Accioly de Souza \\ Department of Urology, Hospital Federal da Lagoa, Rio de Janeiro, Brazil \\ Email: joseanacletojunior@gmail.com
}

Received September 9, 2011; revised November 15, 2011; accepted December 3, 2011

\begin{abstract}
The clear cell carcinoma is a relatively rare tumor, represented approximately $85 \%$ by renal cell carcinoma (RCC), but has a characteristic of early metastatic, which sometimes spread to unusual places. Metastatic tumors in the paranasal sinuses are very rare. This case report a 65 years-old patient who presented sinusitis and epitaxis as a first sign of renal cell carcinoma with metastasis to the right maxillary sinus, which was opereted at Lagoa Hospital-RJ and strengthen the inclusion of this disease in the differential diagnosis of sinus disease. The renal cell carcinoma is a relatively rare tumor, representing approximately $3 \%$ of malignant tumors. About a third of patients with renal cell carcinoma have metastasis at diagnosis. The sinuses are a rare location of metastasis. The maxillary sinuses and the paranasal sinuses are most commonly affected by metastatic tumors to the sinuses region. The most frequent primary tumor to metastasis to paranasal sinuses is the renal cell carcinoma. This report highlights the rarity of the case and the importance in the differential diagnosis of sinus disease.
\end{abstract}

Keywords: Renal Cell Carcinoma; Metastasis; Sinuses; Epistaxis

\section{Introduction}

The clear cell carcinoma is a relatively rare tumor with an incidence of 9.6 per 100,000, represented approximately $85 \%$ by renal cell carcinoma (RCC) [1].

About $30 \%$ of patients have metastasis at diagnosis and $40 \%$ to $50 \%$ will develop distant metastasis after initial diagnosis.

The renal cell carcinoma is characterized by early metastatic spread and short survival in part by the limited treatment options, resulting in poor response to chemotherapy and radiotherapy. Regarding distant metastasis, the organ most affected is the lung, followed by bone and liver [1].

The pranasal sinuses are a rare location of metastasis. Renal cell carcinoma is the primary tumor which most frequently metastasis in the sinusal region [2].

Symptoms are unspecific, but the epistaxis corresponds the most common sign due to the high vascularizations of the tumor. Prognosis is uncertain. The survival rate fluctuates between $15 \%-30 \%$ at 5 years [2].

Because of this rarity, the literature shows few reports of this entity.

\section{Objective}

The objective of this study is to report a case of sinusitis and epistaxis as a first sign of renal cell carcinoma with metastasis to the right maxillary sinus and strengthen the inclusion of this disease in the differential diagnosis of sinus disease.

\section{Case Report}

A 65 years-old male patient, white, ex-smoker (19571971) and hypertension, admitted to the otolaryngology clinic of the Lagoa Hospital on 09/10/09 with a history of intermittent episodes of epistaxis and sinusitis for four months. He had no other complaints from back pain. Initially treated with amoxicillin $500 \mathrm{mg}$ for 14 days showed no significant improvement.

$\mathrm{He}$ returned for reassessment days referring persistence of symptoms and progressive proptosis (Figure 1).

The patient underwent nasal endoscopy that diagnosed a tumor in the right maxillary sinus and underwent biopsy. Further evaluation with computed tomography (CT) of paranasal sinuses showed the lesion in the right nasal cavity (Figure 2). The biopsy showed clear cell carcinoma (Figure 3), confirmed later by immuno-histquimico (CD 10, EMA, Vimentin, and AE1/AE3).

During systemic evaluation (abdominal ultrasound, CT of the abdomen and chest CT), there was respectively: solid mass within the left kidney suggestive of renal cell 


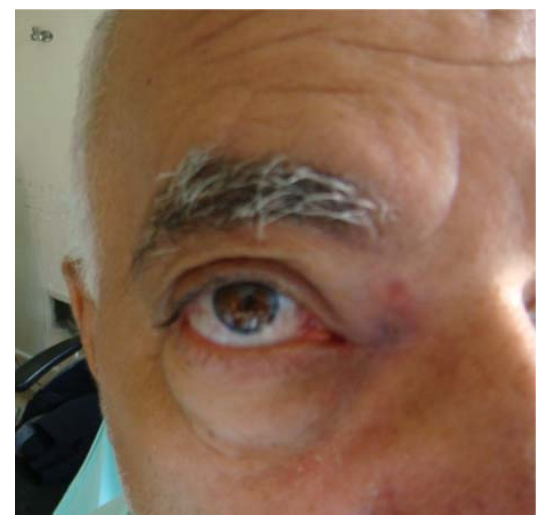

Figure 1. Image showing proptosis of the right eye.

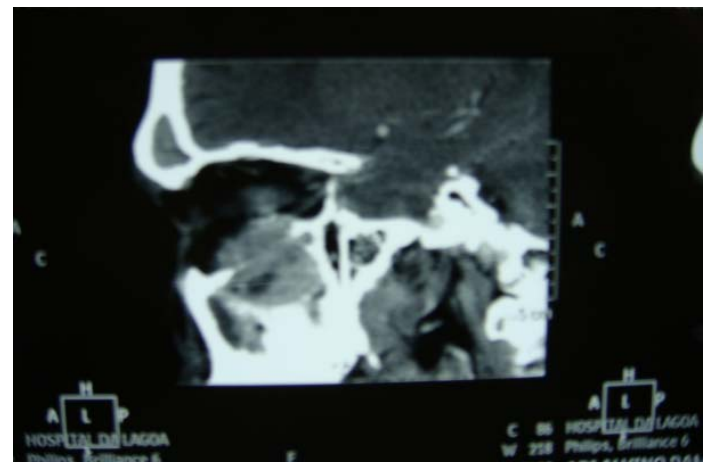

Figure 2. CT scan showing lesion in the right maxillary sinus floor with invasion of the right orbit.

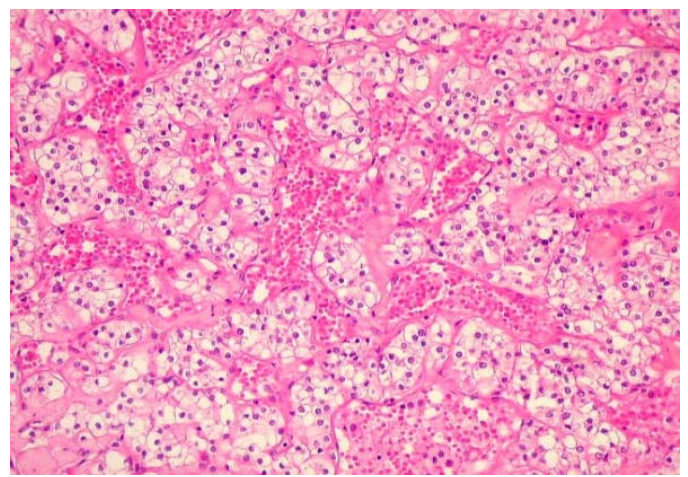

Figure 3. Histologic image_clear cell renal carcinoma.

tumor (Figure 4), bone lesion in the lumbar spine consistent with metastatic disease, and absence of pulmonary nodules suggestive of metastasis.

The patient underwent laparoscopic radical nephrectomy $(14 / 12 / 09)$ of the left kidney and anatomical studyPart pathological kidney showed a weight of 235 gram, measuring $12.5 \times 7.5 \times 5.0 \mathrm{~cm}$ and showing in its middle portion a yellow tumor, heterogeneous and soft, measureing $5.0 \mathrm{~cm}$ in greatest axis. A microscopy confirmed clear cell variant of renal cell carcinoma, Fuhrman grade III with extensive necrosis and capsular invasion at the Gerota's fascia (Figure 5).

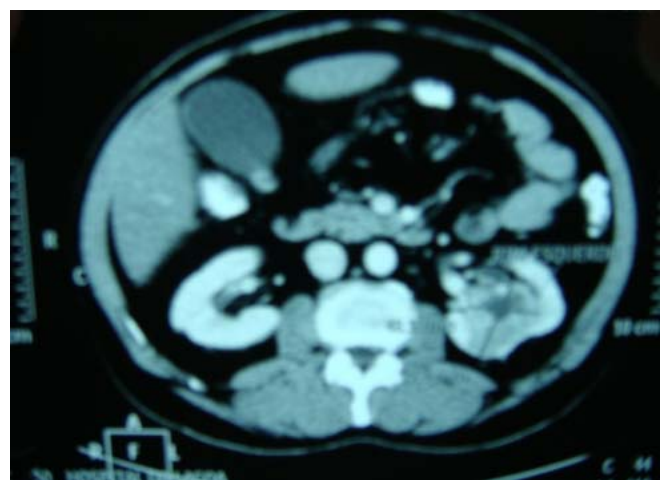

Figure 4. Computed tomography of the abdomen showing a solid tumor in the left kidney.

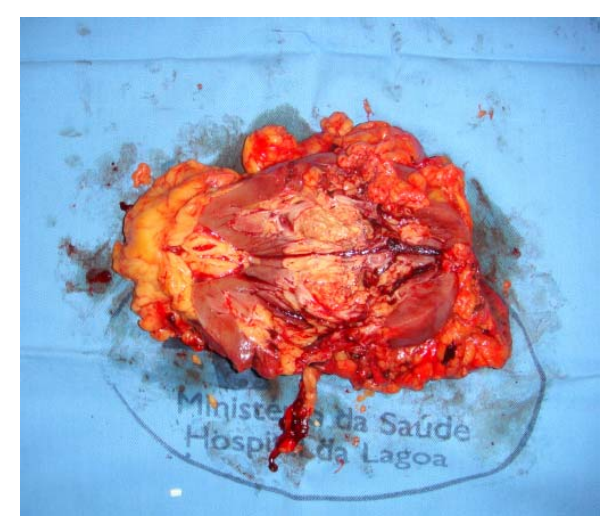

Figure 5. Surgical specimen showing solid tumor (RCC) in left renal sinus.

After the surgery, began systemic therapy with sorafenib $200 \mathrm{mg} 2$ pills of 12/12 hours and radiotherapy for control of secondary implant in the maxillary sinus and bone lesion in the lumbar spine.

Although, the therapeutic measures were implemented in an attempt to control the disease and increased survival, the patient died four months after surgery.

\section{Discussion}

The renal cell carcinoma is a relatively rare tumor, representing approximately $3 \%$ of all malignant tumors [3].

About a third of patients with renal cell carcinoma have metastasis at diagnosis. Of the remaining two thirds, about $50 \%$ will have disease recurrence after treatment of the initial lesion [4].

The development of metastatic disease is a selective and regulated process. Only a subpopulation of cells in the primary tumor has the properties of genetic, biochemical, immunological and biological for metastasis [5].

The major route of spread of RCC is hematogenous, via the renal vein, which communicates with the superior vena cava and right atrium and lung. Considering that hematogenous spread is the main cause of distant metas- 
tases, microvascular invasion can be essential for metastasis. [1]

A study by Dall'Oglio observed recurrence in 28 of 59 patients $(47 \%)$ with microvascular invasion after radical or partial nephrectomy, while only 11 of $171(6 \%)$ without microvascular invasion had recurrence.

Since the middle of last century, multiple institutions have correlated the size of the primary RCC with significant risk of developing synchronous and asynchronous metastasis. The renal cell carcinoma with a diameter of $3 \mathrm{~cm}$ or less, has lower potential to cause metastasis. However, the cancer spreads to other organs in a small number of cases, which can't be ignored.

The risk of metastatic disease in tumors smaller than 3 $\mathrm{cm}$ is negligible. Klatte et al. reported that 20 of the 392 cases $(5.1 \%)$ with tumors 2.1 to $3 \mathrm{~cm}$ had metastasis. Kunkle et al. was only one case of metastasis synchronous and asynchronous after nearly another 500 surgeries on tumor between $2-3 \mathrm{~cm}$. Haruki et al published a series of 165 cases of RCC $3 \mathrm{~cm}$ or less, in which 10 cases of metastasis $(6.06 \%)$ were observed. Houston et al reported a retrospective study of 2367 cases of RCC, where 162 patients had documented metastatic disease. Only 1 of 781 patients $(0.1 \%)$ with a primary tumor smaller than $3 \mathrm{~cm}$ had metastatic RCC in the presentation. When the primary tumor size was $3 \mathrm{~cm}$ or more, the risk of M1 RCC gradually increased from $1.8 \%$ to $17.0 \%$ in patients with tumors 3 to 3.9 and $7 \mathrm{~cm}$ or more, respectively.

Regarding distant metastasis, the organs most affected are the lungs followed by bone and liver [2].

However, as metastasis has been reported in the literature for other less common sites such as pancreas, vagina, skin and sinuses.

The maxillary sinuses and the paranasal sinuses are most commonly affected by metastatic tumors to the sinonasal region, followed in frequency the ethmoid sinus, frontal and sphenoid [6].

The paranasal sinuses are a rare location of metastasis. The most frequent primary tumor to metastasize to paranasal sinuses is the renal cell carcinoma [2].

The secondary tumor of the paranasal sinuses is very rare with less than 100 cases reported in the literature up to 2001 [7].

A literature review revealed 169 studies involving 123 cases of secondary tumors in paranasal sinuses. Of these, 69 cases had the RCC as the primary site, followed by bronchogenic carcinoma (15 cases), breast cancer (14 cases), thyroid cancer (13 cases) and prostate cancer (12 cases) [8].

Kaminski et al. documented 46 cases of metastatic tumors to the head and neck and only four for the nasal cavity and paranasal sinuses. Of these, only one case of RCC with metastasis to the maxillary sinus in a man of 69 years, which was treated with multiple palliative re- sections [9].

Symptoms are unspecific, but the epistaxis corresponds the most common sign due to the high vascularizations of the tumor. Prognosis is uncertain. The survival rate fluctuates between $15 \%-30 \%$ at 5 years [2].

Depending on the affected anatomical area, patients might have symptoms similar to the ones presented with a primary tumor of the area. In many occasions, only a biopsy will give a final diagnosis and provide the treating physician with a pathway to follow [6].

The initial evaluation of the tumor in the nasal cavity should follow the following sequence: nasal endoscopy, $\mathrm{CT}$ of the paranasal sinuses and the tumor biopsy (gold standard).

The evaluation system should be immediately performed to determine the extent of metastatic disease and the therapeutic setting.

Patients with metastasis to the nasal cavity are candidates for surgical resection of primary tumor, even in the presence of other metastasis.

Although we have very little data in the literature about RCC and metastasis to paranasal sinuses, the recommended treatment of metastatic RCC is radical nephrectomy/cytoreductive. First-line treatment is surgical, due to low radiosensitivity, with radiation therapy as a possible second line [10-11].

The removal of primary renal cell carcinoma can lead to regression of secondary lesion in $1 \%$ to $2 \%$ of cases, as well as specific cancer survival improves significantly, regardless of histological type, tumor size and patient age [12].

Our service was the treatment of metastatic lesion with radiation therapy due to non-resectability of the lesion and then performed left laparoscopic radical nephrectomy followed by adjuvant treatment with Sorafenib.

\section{Conclusions}

Metastasis to the nasal cavity as the first presentation of a renal clear cell carcinoma is rare, although the diagnosis of a metastatic lesion alone represents a sign of poor prognosis, the evolution of knowledge in oncology has allowed increased survival of cancer patients.

This review highlights the rarity of the case and the importance in the differential diagnosis of sinus disease.

\section{REFERENCES}

[1] A. J. Wein, L. R. Kavoussi, A. C. Novick, A. W. Partin and C. A. Partin, "Campbell-Walsh Urology," Saunders: An Imprint of Elsevier, Philadelphia, 2007.

[2] B. T. Muros, J. R. S. Romero, J. G. B. Rodriguez and R. B. Parrilla, "Maxillary Sinus Metastasis of Renal Cell Carcinoma," ACTAS Urologicas Espanolas, Vol. 30, No. 9, 2006, pp. 954-957. 


\section{doi:10.4321/S0210-48062006000900015}

[3] G. Fischetti, S. Cuzari, P. Leone, P. De Martino, M. Musy, S. Mariane, A. Fraioli and M. A. Valentini, "Immunotherapy in the Management of Metastatic Renal Carcinoma," Minerva Urologica e Nefrologica, Vol. 54, No. 2, 2002, pp. 113-117.

[4] J. Avolius, D. Astorokos, C. Avlovich and P. Usso, "Resection of Metastatic Renal Cell Carcinoma," Journal of Clinical Oncology, Vol. 16, No. 6, 1998, pp. 2261-2266.

[5] H. A. Koutnouyan, G. J. Rumore and J. M. Kahn, "Skull Metastasis from Renal Cell Carcinoma. Case Report and Literature Review," Annals of Otology, Rhinology and Laryngology, Vol. 107, No. 7, 1998, pp. 598-602.

[6] C. S. Duque-Fisher, R. Casiano, A. Vélez-Hoyos and A. F. Londoño-Bustamente, "Metastasis to the Sinonasal Region," Acta Otorrinolaringologica Espanola, Vol. 60, No. 6, 2009, pp. 428-431. doi:10.1016/j.otorri.2009.06.003

[7] J. M. Del Portal, F. Anaya, E. Solis, J. Segura, A. Robles and J. M. Castilla, "Transitional Vesical Cell Carcinoma Metastatizing to the Sphenoid Sinus," Acta Otorrinolaringologica Espanola, Vol. 57, No. 2, 2006, pp. 118-120.

[8] A. Precher, M. Santis and D. Brors, "Renal Cell Carcinoma Presenting with Orbital Metastases," Laryngorhi- nootologie, Vol. 80, 2001, pp. 583-594.

[9] B. Kaminski, J. Kobirorska-Nowak and S. Bien, "Distant Metastases to Nasal Cavities and Paranasal Sinuses, from the Organs outside the Head and Neck," The Polish otolaryngology, Vol. 62, No. 4, 2008, pp. 422-425.

[10] F. L. Heldwein, B. Escudier, G. Smyth, C. A. Souto and G. Vallancien, "Metastatic Renal Cell Carcinoma Management," International Journal of the Brazilian Society of Urology, Vol. 35, No. 3, 2009, pp. 256-270. doi:10.1590/S1677-55382009000300002

[11] J. B. Morvan, J. B. Veyrières, O. Mimouni, O. Cathelinaud, L. Allali and P. Verdalle, "Clear-Cell Renal Carcinoma Metastasis to the Base of the Tongue and Sphenoid Sinus: Two Very Rare Atypical ENT Locations," European Annals of Otorhinolaryngology, Head and Neck Diseases, Vol. 128, No. 2, 2011, pp. 91-94. doi:10.1016/j.anorl.2010.11.003

[12] L. Zini, U. Capitanio, P. Perrotte, C. J. Claudio, S. F. Shariat, P. Arjane, H. Widmer, F. Montorsi, J. J. Patard and P. I. Karakiewicz, "Population-Based Assessment of Survival after Cytoreductive Nephrectomy versus No Surgery in Patients with Metastatic Renal Cell Carcinoma," Urology, Vol. 73, No. 2, 2009, pp. 342-346. doi:10.1016/j.urology.2008.09.022 